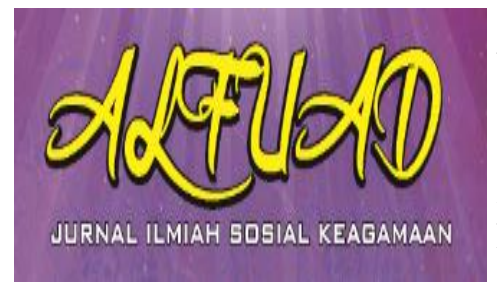

ALFUAD JOURNAL, 4 (1), 2020, (35-44)

(E-ISSN 2714-7606 P-ISSN 2614-4786 )

Available online at

http://ecampus.iainbatusangkar.ac.id/ojs/index.php/alfuad

\title{
IKONISASI PAKAIAN 'ISLAMI': BENTUK KOMUNIKASI NON VERBAL DI LINGKUNGAN PERGURUAN TINGGI ISLAM
}

\section{Zafirah Quroatun 'Uyun}

Institut Agama Islam Negeri Batusangkar, Indonesia

E-mail: zafirah@iainbatusangkar.ac.id

\begin{abstract}
Iconization in an institution, especially for university there are some consequences. In addition to influencing visions and missions, lifestyles, religions, even cultural industry provides its own style. As with 'Islamic' clothing in several Islamic universities that begin to process into an icon due to negotiation of religious and cultural values, communication patterns change from just talking, writing and discourse to a form of non-verbal communication which is contains codes and symbols. This research tries to elaborate 'Islamic' clothing iconization forms by describing a set of codes and symbols of non-verbal communication using 'Islamic' clothing. Analysis of the influence of lifestyle, religion, customs will be described using the method of literature and observation. This research found that the intersection between industrialization of culture, lifestyle and religion with non-verbal communication had consequences for iconization.
\end{abstract}

Keywords: Iconization, Non-Verbal, Communication, Lifestyle, Cultural Industry

\section{PENDAHULUAN}

Islam sebagai agama paripurna telah mengatur segala aspek kehidupan. Dari yang terbesar dalam kelompok suprasistem seperti politik dan ekonomi hingga kelompok terkecil seperti cara berpakaian. Dalam industrialisasi budaya, cara berpakaian merupakan gaya hidup yang wajib dipertontonkan kepada khalayak luas demi berputarnya roda industri. Media menjadi kunci dibalik kesuksesan sebuah industri budaya meski bersifat manipulatif. Pakaian 'Islami' merupakan salah satu bentuk manipulasi industrialisasi budaya, sehingga makna dan bentuk pakaian 'islami' tidak ada yang baku. Makna dan bentuk ini terus berubah seiring pergeseran porsi prioritas konsumsi budaya, gaya hidup dan agama. Seseorang yang cenderung memprioritaskan konsumsi budaya misalnya, akan mempertimbangkan motif pakaian 'Islami' yang dikenakan, bukan pada kepentingan syar'i tetapi lebih kepada kepentingan identitas budaya yang ingin ditunjukkan.

Indonesia merupakan negara dengan populasi penduduk muslim terbesar di dunia. Dalam laporan Pew Research, 
sebuah lembaga riset global pada 2010 telah tercatat Indonesia menempati urutan teratas sebagai negara dengan populasi muslim terbesar di Dunia. Pada tahun itu tercatat 203,8 juta jiwa lebih penduduk Indonesia merupakan muslim (Pew Research Center, 2011). Pernyataan ini juga diperkuat oleh pidato kenegaraan Presiden Jokowi "Sebagai bangsa yang besar dengan penduduk Muslim terbesar di dunia mempunyai ratusan suku dan ribuan pulau, bangsa Indonesia harus percaya diri untuk meraih kemajuan, mengejar ketertinggalan dan mewujudkan kejayaan," (16/8/2017). Indonesia dengan mayoritas pemeluk agama Islam merupakan sumber inspirasi dan komoditas menggiurkan bagi pengiklan dalam mengemas produknya agar menjadi laku di pasaran. dengan bekal "potensi" itulah, tak jarang pengiklan ataupun pembuat produk iklan memanfaatkannya sebagai sesuatu yang dapat dijadikan barang dagangan, meski harus melakukan upaya komodifikasi agama, yakni menjadikan agama dan "komponen" di dalamya sebagai bagian komoditas yang layak diperjualbelikan di pasaran. Dalam konteks ini, pakaian 'islami' mengalami perubahan makna dan bentuk akibat bercampur baurnya kepentingan agama, budaya dan pasar/kapital. Media sebagai subjek hantaran ketiga kepentingan akhirnya menciptakan (pseudo) relialitas semu bagi masyarakat/khalayak. Apa yang terjadi kemudian adalah masyarakat hanya sebagai objek kapital, mengikuti selera pakaian 'Islami' berdasarkan gaya hidup mode/fashion.

Perguruan tinggi Islam sebagai salah satu instituti pendidikan tinggi, memiliki corak yang khas dalam hal pendalaman aqidah islam. Diksi pakaian 'islami' menjadi salah satu diskursus yang banyak diperdebatkan. Beberapa berpendapat cara berpakaian termasuk dalam akhlak yang menghiasi agama, sementara yang lain mengatakan bahwa pakaian harus menjadi pembahasan wajib dalam setiap penyampaian pokok-pokok ajaran islam. Hal ini menjadi semakin menarik manakala kepentingan pasar/kapital dan negosiasi budaya lokal ikut bermain. Pendapat baru bermunculan seperti pakaian 'islami' itu merupakan bentuk modelfashion. Perguruan tinggi Islam masing-masing akhirnya memiliki standar tersendiri dalam memaknai pakaian 'Islami'. Hal ini tidak luput dari terpaan pengaruh media komunikasi. Apapun bentuk media itu baik media konvensional maupun media online, ikonisasi muncul dari informasi yang disebarluaskan. Video, selebaran, baliho, poster, dan lain sebagainya yang bermuatan visi dan misi melalui iklan persuasi, kode, gambar, foto, logo, warna dan saturasi masing-masing perguruan tinggi Islam memberikan corak 
dan pembentukan makna terhadap pakaian 'Islami'. Pada tahap ini, tidak perlu menunjukkan secara lisan maupun tulisan bentuk baku pakaian 'Islami', masyarakat dan perguruan tinggi Islam yang bersangkutan akan merekonstruksi informasi tersebut menjadi sebuah makna baru- dalam bentuk komunikasi non verbal-. Disadari atau tidak hal ini yang akan mengarahkan konsekuensi ikonisasi.

\section{METODE}

Adapun metode penelitian kajian pustaka atau studi kepustakaan yaitu berisi teori teori yang relevan dengan masalah masalah penelitian. Pada bagian ini dilakukan pengkajian mengenai konsep dan teori yang digunakan berdasarkan literatur yang tersedia, terutama dari artikel-artikel yang dipublikasikan dalam berbagai jurnal ilmiah. Kajian pustaka berfungsi untuk membangun konsep atau teori yang menjadi dasar studi dalam penelitian. Kajian pustaka atau studi pustaka merupakan kegiatan yang diwajibkan dalam penelitian, khususnya penelitian akademik yang tujuan utamanya adalah mengembangkan aspek teoritis maupun aspek manfaat praktis. Sehingga dengan menggunakan metode penelitian ini penulis dapat dengan mudah menyelesaikan masalah yang hendak diteliti.

\section{HASIL DAN PEMBAHASAN}

\section{Ikonisasi Pakaian 'Islami’: Antara Kode dan Mode}

Ikonisasi merujuk pada proses pembentukan ikon. Kata ikon berasal dari bahasa Latin yaitu icon yang berarti arca atau patung atau gambar atau patung yang menyerupai contohnya (Verhoeven, 1969). Kata ikon selanjutnya dipakai oleh Pierrce sebagai istilah semiotika yaitu untuk menyebut tanda yang penandanya memiliki hubungan kemiripan dengan obyek yang diacunya. Kata ikon kemudian dipakai dalam keilmuan linguistik dengan maksud "to refer to signals morse physical form closely correspondens to characteristic to which they refers" (Crystal, 1980) yang dapat diartikan sebagai untuk menyebut tanda yang bentuknya fisiknya memiliki kaitan yang erat dengan sifat khas dari apa yang diacunya (Sudaryanto, 1989).

Dengan demikian, pengertian ikon dapat dirumuskan dengan lebih tegas yaitu satuan lingual yang bentuknya mirip dengan realitas yang diacunya atau satuan lingual yang bentuknya mencerminkan realitas yang diacunya. Meski kajian ikonisasi merupakan rumpun ilmu lingusitik dan baru digunakan untuk objek penelitian bahasa, tetapi objek materiil bahasa yang lebih kecil adalah kode. Dalam bahasa, istilah morse dan kode sudah tidak asing lagi. Dalam ranah 
komunikasi, ikonisasi melibatkan beberapa kode dan transaksi makna yang tersirat, yang disebut dengan komunikasi non verbal.

Mode atau yang lebih dikenal dengan istilah fashion merupakan fenomena gaya hidup (Ibrahim, 2007) yang mana menurut Ibrahim, masyarakat konsumen Indonesia tumbuh beriringan dengan sejarah globalisasi ekonomi dan transformasi kapitalisme konsumsi. Hal ini ditandai dengan menjamurnya pusat perbelanjaan seperti mall, industri waktu luang, industri mode atau fashion, industri kecantikan, industri kuliner, industri nasihat, industri gosip, industri media, kawasan hunian mewah, real esatate, gencarnya iklan barang-barang supermewah, liburan wisata ke luar negeri, berdirinya sekolah-sekolah mahal, kegandrungan terhadap merek asing dan makanan serba instant (fast food) Fashion berasal dari bahasa Latin, factio, yang artinya membuat atau melakukan. Karena itu, arti kata asli fashion mengacu pada kegiatan; fashion merupakan sesuatu yang dilakukan seseorang, tidak seperti dewasa ini, yang memaknai fashion sebagai sesuatu yang dikenakan seseorang. Arti asli fashion pun mengacu pada ide tentang fetish atau obyek fetish. Kata ini mengungkapkan bahwa butir-butir fashion dan pakaian adalah komoditas yang paling di-fetishkan, yang diproduksi dan dikonsumsi di masyarakat kapitalis. Polhemus dan Procter (Barnard, 2006) menunjukkan bahwa dalam masyarakat kontemporer Barat, istilah fashion sering digunakan sebagai sinonim dari istilah dandanan, gaya dan busana/pakaian.

Pakaian 'islami' sebagai salah satu bentuk mode yang dikonstruksi oleh industri media dan industrialisasi budaya sesungguhnya tidak memiliki agama. Artinya pakaian sendiri secara harfiah tidak ada kaitannya dengan agama karena ia merupakan sebuah benda. Menjadi akar masalah jika tindakan kita yang berkaitan dengan cara berpakaian membawa simbolsimbol agama tertentu dan identik dengan kaum tertentu. Perguruan tinggi Islam misalnya yang mengusung konsep Islam, sudah barang tentu harus menyesuaikan segala kode, nilai dan simbol-simbol ajaran islam. Pembahasan ini juga masuk pada ranah hukum masing-masing agama.

Dalam agama islam, tolak ukur dan kacamata analisa harus memakai dalil-dalil yang bersumber dari alquran dan al-hadist. Dalil yang berbunyi “Barangsiapa yang menyerupai suatu kaum, maka dia termasuk bagian dari mereka." (HR. Ahmad 2: 50 dan Abu Daud no. 4031. Syaikhul Islam dalam Iqtidho“ 1: 269 mengatakan bahwa sanad hadits ini jayyid/bagus. Syaikh Al Albani mengatakan bahwa hadits ini shahih sebagaimana dalam Irwa'ul Gholil no. 1269),serta “Bukan termasuk golongan kami 
siapa saja yang menyerupai selain kami" (HR. Tirmidzi no. 2695. Syaikh Al Albani mengatakan bahwa hadits ini hasan).

Dalam al-Quran, tidak ada satu ayat pun yang menunjukkan makna kewajiban menggunakan pakaian dengan model, bentuk atau warna tertentu, yang ada hanya kewajiban menutup aurat dan menjulurkan pakaiannya kebawah dengan tidak menyerupai suatu kaum (QS. Al-A'raf; 26 dan Q.S Al-Ahzab;59). Adapun bentuk, model, warna dan lainnya diserahkan kepada masing-masing individu sesuai dengan kebutuhannya, yakni untuk melindungi tubuh dari sengatan terik matahari atau menjaga tubuh dari cuaca dingin, untuk menghias diri supaya terlihat indah (tajammul wa tazayyun) atau menjaga diri dari serangan senjata atau benda-benda lain. Untuk melestarikan kebudayaan tertentu dan menyimbolkan kelompok masyarakat tertentu diserahkan kepada masing-masing individu dan atau instansi -dalam pembahasan ini perguruan tinggi Islam- selama tidak keluar dari koridor syara'.

Pakaian 'Islami' terjebak antara kepentingan kode dan mode. Untuk alasan sakralisasi dan simbolisasi agama, pakaian 'Islami' memang tidak menemui perdebatan berarti. Lain halnya dengan kepentingan kode dan mode yang dikonstruksi industri budaya serta media. Pada satu titik, sebuah institusi perguruan tinggi Islam memang memiliki visi dan misi yang khas sehingga komunikasi non verbal yang disampaikan melalui pakaian 'Islami' berarti perpaduan antara nilai agama Islam, nilai budaya lokal dan visi misi yang diembannya. Tetapi ketika industrialisasi budaya ikut berperan, kode yang ingin ditunjukkan kepada khalayak masyarakat terdistorsi dengan mode yang merupakan produk sebuah industri budaya dan media. Hal ini menjadi sebuah keniscayaan mengingat industri selalu mencari celah untuk kegiatan produksi, distribusi dan konsumsi. Yang terjadi selanjutnya adalah pemaksaan logika agama ke dalam logika pasar yang biasa disebut dengan komodifikasi (Mosco,1996). Ketika kerudung, jilbab, gamis, baju koko (dengan berbagai model, pola, corak, warna) kian menjadi salah satu ikon mode di perguruan tinggi 'Islam', perguruan tinggi Islam lambat laun akan membentuk resistensi dengan menghadirkan ikonisasi yang tidak disadari.

\section{Industrialisasi Budaya sebagai Pencipta Gaya Hidup}

Di era revolusi industri 4.0, potensi manusia tidak hanya bersaing dengan mesin. Manusia-manusia lainnya saling bersaing demi menduduki posisi tertinggi bahkan hanya untuk mempertahankan posisi. Usaha-usaha yang dilakukan beragam, mulai dari inovasi dibidang 
keilmuan, memperbanyak skill, dan yang menjadi sorotan adalah memperbaiki penampilan diri. Penampilan diri disebutsebut sebagai inti manusia modern era revolusi industri 4.0. karena itu, revolusi industri 4.0 berjalan beriringan dengan industri budaya dan media.

Dalam sebuah institusi yang memasukkan konsep revolusi industri, penampilan diri adalah segalanya. Urusan penampilan atau presentasi diri ini sudah lama menjadi perbincangan sosiologi dan kritikus budaya. Erving Goffman, misalnya dalam The Presentation of Self Everyday Life (1959). Ia mengemukakan bahwa kehidupan sosial terutama terdiri dari penampilan teatrikal yang diritualkan, yang kemudian lebih dikenal dengan pendekatan dramaturgi (dramatugical approach). Manusia seolah-olah sedang bertindak di atas sebuah panggung. Bagi Goffman, berbagai penggunaan ruang, barang-barang, bahasa tubuh, ritual interaksi sosial tampil untuk memfasilitasi kehidupan sosial sehari-hari (Ritzer, 2005).

Merujuk pada revolusi industri 4.0, penampilan diri itu justru mengalami estetisasi, "estetisasi kehidupan seharihari”, bahkan tubuh/diri (body/self) pun justru mengalami estetisisasi tubuh. Tubuh/diri dan kehidupan sehari-hari pun menjadi sebuah proyek, benih penyemaian mode. "Kamu modis maka kamu ada!" adalah ungkapan yang mungkin cocok untuk melukiskan kegandrungan manusia modern akan mode. Itulah sebabnya industri mode sebagian besar adalah industri penampilan.

Menurut Chaney, penampakan luar menjadi salah satu situs yang penting bagi industri mode. Hal-hal permukaan akan menjadi lebih penting daripada substansi. Gaya dan desain menjadi lebih penting daripada fungsi. Gaya menggantikan subtansi. Kulit akan mengalahkan isi. Pemasaran penampakan luar, penampilan, hal-hal yang bersifat permukaan atau kulit akan menjadi bisnis besar industri. Lebih lanjut Chaney mengingatkan bagaimana para politisi, selebriti, artis pertunjukan, dan figur-figur publik lainnya akan terus berusaha memanipulasi penampakan luar citra mereka (gaya hidup mereka) untuk merekayasa kesepakatan dan mendapatkan dukungan. Sementara posisi kita hanya sebagai penikmat dan target pasar. Budaya dan standar manusia mengalami perubahan ke arah industri. Chaney juga mengatakan bahwa semua yang kita miliki akan menjadi budaya tontonan (a culture of spectacle). Semua orang ingin menjadi penonton dan sekaligus ditonton. Ingin melihat tetapi sekaligus juga dilihat (Chaney, 2004). Di sinilah mode mulai menjadi modus keberadaan manusia modern: Kamu modis maka kamu ada! Jika kamu tidak modis, siap-siaplah untuk dianggap tidak ada; diremehkan, 
diabaikan, atau mungkin dilecehkan. Itulah sebabnya manusia era revolusi industri, perlu bersolek atau berias diri. Jadilah kita sebuah masyarakat pesolek (dandy society). Di kalangan umat Islam, misalnya kini mulai marak iklan dan industri jasa yang menawarkan 'wisata religius', berdirinya kafe-kafe khusus muslim, berdirinya sekolah Islam mahal, menjamurnya konter berlabel Exclusive Moslem Fashion, kegandrungan kelas menengah atas akan Moslem Fashion Show dan berdirinya pusat pusat perbelanjaan yang memanfaatkan sensibilitas keagamaan untuk keuntungan bisnis.

Kini gaya hidup demikian bukan lagi monopoli artis, model, peragawan(wati), atau selebriti yang memang sengaja mempercantik diri untuk tampil di panggung. Tapi, gaya hidup golongan penganut dandyism itu kini sudah ditiru secara kreatif oleh masyarakat untuk tampil sehari-hari baik ke tempat kerja, seminar, arisan, undangan resepsi pernikahan, ceramah agama, kuliah atau sekadar jalan-jalan.

Sejak awal kemunculannya pada tahun 1930-an, industrialisasi budaya diiniasi sekelompok pemikir Jerman yang melakukan studi di sekolah Frankfurt kemudian lebih dikenal dengan Mazhab Frankfurt. Kelompok ini telah mengadakan studi kritis tentang komunikasi massa dan budaya, dan menghasilkan teori kritis tentang industri budaya. dimulai dari Jerman ke Amerika Serikat, Mazhab Frankfurt mengamati fenomena tumpah ruahnya budaya media melalui film, musik populer, radio, televisi, dan bentuk-bentuk lain dari budaya massa. Mazhab Frankfurt menciptakan term industri budaya untuk menandai sebuah proses industrialisasi budaya produksi massa dan imperatif komersial yang menggerakkan sistem. Para teoris ini menganalisis semua artefak budaya media massa dalam konteks produksi industri, yang mana artefak tersebut menunjukkan kesamaan bentuk sebagai produksi massa: komodifikasi, standarisasi, dan massifikasi (Hesmondhalgh, 2002). Hal ini mengakibatkan gaya hidup yang terbentuk adalah semu homogen. Artinya produk yang tercipta dipaksa satu selera dan ia merupakan rekayasa gabungan antara budaya, media dan industri .

\section{Resistensi Perguruan Tinggi Islam}

Menghadapi fenomena mode pakaian 'Islami' sebagai akibat dari industrialisasi budaya, institusi harus memiliki semacam resistensi. Perguruan tinggi Islam misalnya, tidak hanya mencukupkan diri dengan mengurai visi dan misi, dalam aturan dan program mata kuliah tetap harus diberi penegasan tentang keimanan, cara berpakaian syar'i dan cara pandang dengan 
secara kontinyu membentuk pola pikir dan pola sikap sesuai ajaran Islam. Meski Perguruan tinggi Islam merupakan etintas majemuk yang merupakan proponen dari kajian budaya, keislaman dan pendidikan, tetapi masih bisa dijelaskan bahwa substansi dan praktek ajaran Islam menjadi faktor penting pembentukan resistensi terhadap geliat industrialisasi budaya dan media. Elaborasi visi misi perguruan tinggi Islam beserta ajaran-ajaran Islam termanifestasi menjadi symbolic resistance (Jensen, 2017) yang dipercayai dapat menjadi jawaban kultural, respon dan solusi kreatif bagi Perguruan tinggi Islam dalam melakukan resistensi terhadap budaya dominan.

Kajian mengenai resistensi dalam disipilin ilmu sosial pada mulanya memang mengenai gerakan sosial. Bergesernya paradigma keilmuan membuat resistensi dapat ditarik ke variabel yang lebih luas seperti perguruan tinggi Islam. Resistensi merujuk pada penolakan untuk menerima identitas sosial yang ditawarkan ideologi dominan dan kontrol sosial yang menyertainya. Penolakan terhadap ideologi, juga terhadap makna dan kontrol, memang bisa jadi tidak menantang sistem sosial namun melawan inkorporasi serta menjalankan dan memperkuat makna perbedaan sosial yang menjadi pra-syarat bagi tantangan sosial lainnya (Jensen \& Sune, 2017).
Berdasarkan ulasan peneliti dan definisi para ahli, pernyataan-pernyataan yang ingin penulis tegaskan adalah sebagai berikut (1) bahwa sangat mungkin di era industrialisasi budaya, percampuran budaya lokal dan budaya pop membawa konsekuensi negosiasi kepentingan perguruan tinggi Islam, motif individu, selera pasar dan budaya lokal yang berkembang sehingga pemaknaan terhadap pakaian 'Islami' menjadi lebih luas dari sekedar mode dan cara berpakaian, (2) bahwa bisa jadi perguruan tinggi Islam telah melakukan resistensi terhadap industrialisasi budaya dan selera pasar yang terus berubah melalui penggambaran media namun kemauan untuk bersaing dengan dunia global dan ketaatan terhadap visi misi serta aqidah Islam telah terdistorsi sehingga mengahasilkan pandangan yang beragam terhadap kebutuhan pakaian 'Islami', (3) serta resistensi di perguruan tinggi Islam tidak terjadi dengan serangkaian efek domino, ia perlahan menemukan bentuknya melalui kesadaran setiap individu sebagai komunikator dan komunikan aktif hingga ikonisasi pakaian 'Islami' menjadi bentuk komunikasi non verbal "saya mengikuti ajaran Islam, saya dari perguruan tinggi Islam $\mathrm{x}$, saya menjunjung tinggi budaya lokal, saya penikmat mode dan saya menjaga diri dari gempuran budaya pop". 


\section{KESIMPULAN}

Ikonisasi pakaian 'Islami' di perguruan tinggi Islam setidaknya menghasilkan tiga pandangan yang berbeda. Pertama, persinggungan antara kepentingan agama, budaya, gaya hidup, dan perguruan tinggi Islam menghasilkan respon yang kurang menguntungkan pihak perguruan tinggi Islam karena dianggap menerobos ajaranajaran Islam dan merusak visi misi. Kedua, beberapa individu justru melihat hal ini sebagai tindakan yang memunculkan resistensi karena dengan kreativitas konsumen sebagai bentuk komunikasi non verbal, industrialisasi budaya, mode dan agama bisa berjalan beriringan tanpa keluar koridor salah satunya. Ketiga, perguruan tinggi Islam akan mengambil langkah tegas dengan beberapa aturan terkait pakaian 'Islam'. Pada titik empiris tertentu, posisi penulis lebih menyepakati opsi kedua dengan alasan seringkali generasi millenial di era revolusi industri lebih fokus pada gaya hidup dan mode. Pola konsumsi industri budaya pada tahap akut sementara perguruan tinggi adalah tempat berganti generasi dengan banyak kode dan budaya yang bertukar dan saling tumpang tindih (overload). Pada tahap ini, 'pakaian islami' diperguruan tinggi menjadi beragam dengan aturan-aturan tertentu yang disepakati bersama.

\section{DAFTAR PUSTAKA:}

Adlin, A. (Ed.). (2006). Resistensi Gaya Hidup: Teori dan Realitas. Yogyakarta Jalasutra.

Barker, C. (2004). Cultural Studies. Yogyakarta: Kreasi Wacana

Barnard, M. (2006). Fashion as Communication. diterjemahkan oleh Idy Subandy Ibrahim. Fashion sebagai Komunikasi Cara Mengkomunikasikan Identias Sosiasl, Seksual, Kelas dan Gender. Yogyakarta: Jalasutra

Baudrillard, J. (2006). The Ecstasy of Communication. terjemahan oleh Jimmy Firdaus, Ekstasi Komunikasi. Yogyakarta: Kreasi Wacana

Chaney, D. (2004). Lifestyle Sebuah Pengantar Komprehensif. Yogyakarta : Jalasutra

Crystal, D. (1980). A first dictionary of linguistics and phonetics. Boulder, CO: Westview

Featherstone, M. (2001). Postmodernisme dan Budaya Konsumen. Yogyakarta: Pustaka Pelajar

Gillin \& Gillin. (1984). Cultural Sociology. New York: Mac Millan Co.,

Jensen, S. Q. (2017). Towards a Neo Birminghamian Conception of Subculture? History, Challenges, and Future Potentials. Journal of Youth Studies1-18 (online first)

Shadily, H. (1993). Sosiologi Untuk Masyarakat Indonesia. Jakarta: Rineka Cipta

Soekanto, S. (1983). Teori Sosiologi Tentang Perubahan Sosial. Jakarta: Ghalia Indonesia 
Zafirah Quroatun 'Uyun: Ikonisasi Pakaian 'Islami': Bentuk Komunikasi Non Verbal...

Sudaryanto. (1989). Pemanfaatan potensi bahasa : kumpulan karangan sekitar dan tentang satuan lingual bahasa jawa yang berdaya sentuh inderawi. Yogyakarta : Penerbit Kanisius

(1987). Sosiologi: Suatu Pengantar. Jakarta: Rajawali Press
Verhoeven, P. (1969). Liquid Metals: Concepts and Theory. London

Website Pew Research Center tentang moslem all over the world diakses 2 Juli 2019 